\title{
Ofensas verbales en teatro del siglo XVI ${ }^{1}$
}

\section{Verbal offenses in 16 th century theatre}

\author{
AURORA MARTÍNEZ EZQUERRO \\ Universidad de La Rioja, Facultad de Letras y de la Educación, Departamento de Filologías \\ Hispánica y Clásicas, España. Correo electrónico: aurora.martinez@unirioja.es
}

En este artículo se analizan las ofensas verbales registradas en las obras hagiográficas del Códice de Autos Viejos (siglo XVI). Teniendo en cuenta que estas voces son formas lingüísticas integradas en un discurso dramático, el estudio se realiza desde un doble enfoque: el pragmático, que valora los enunciados en la situación en que se produce el acto de comunicación y en el que se establecen unas relaciones entre los interlocutores; y el semántico, que estudia los elementos lingüísticos cuyos significados (agrupados en esferas conceptuales) se muestran en sus diversos contextos y a la luz de los factores sociales de la época. El método aplicado responde, por tanto, al análisis de los vocablos y su intencionalidad (motivaciones, expresividad y funciones lingüísticas) y se complementa con su cotejo en diccionarios históricos de la lengua y en compendios léxicos. En esta investigación se constata que los términos registrados se hallan constreñidos por un teatro en el que predomina el dramatismo religioso y que las necesarias creaciones léxicas, que califican personajes y situaciones con gran fuerza expresiva, se encuentran encorsetadas por la transcripción que conlleva su escritura.

Palabras claves: ofensas verbales, Códice de Autos Viejos, pragmática, semántica, estudio lingüistico.

This article analyzes the verbal offenses registered in the hagiographic works of the Codex of Old Auto Sacramental (16th century). Bearing in mind that these voices are linguistic forms integrated in a dramatic speech, the study is carried out from a double approach: a pragmatic one, that values statements in the situation in which the act of communication takes place in which relations are established among speakers; and a semantic one, which studies the linguistic elements whose meanings (grouped in conceptual spheres) are shown in their different contexts and in light of the social factors of the time. The applied method answers to the study of the words (motivations, expressiveness and linguistic functions) and is complemented by their comparison in historical dictionaries of the language and in lexical summaries. The article states that the registered terms are restricted by a theatre in which religious drama prevails, and that the necessary lexical creations that qualify characters and situations with great expressive force are limited by the transcription that their writing involves.

Key words: verbal offenses, Codex of Old Auto Sacramental, pragmatic, semantics, linguistic study.

${ }^{1}$ Esta investigación se inscribe en el proyecto FFI2010-17870, "La Biblia en el teatro áureo español (I): Del Códice de Autos Viejos a Lope de Vega (BITAE I). Entidad financiadora MICINN. Proyecto I+D Nacional. 


\section{Ofensas verbales, teatro religioso y doctrina Cristiana}

El presente trabajo ofrece el estudio de las ofensas verbales contenidas en el Códice de Autos Viejos ${ }^{2}$ (en adelante, CAV), repertorio que conforma una amplia colección de piezas teatrales destinadas a la representación catequística en el tercer cuarto del siglo XVI. La metodología aplicada en el corpus se basa en un enfoque complementario: el pragmático y el semántico ${ }^{3}$.

Si bien utilizamos diversos términos para referirnos al insulto ${ }^{4}$, partimos de la etimología de esta voz, esto es, 'asalto' o 'ataque' puesto que es sema común a los demás. Es término derivado del latín tardío assalire 'saltar contra algo', 'asaltar' (Corominas y Pascual DCECH 1993), s.v. salir, entiéndase 'saltar contra alguien con ánimo de ofenderlo'. Insulto es un cultismo del siglo XV (Ariza 2009: 32) que originariamente significó 'acometimiento violento o improviso para hacer daño' o 'el daño ocasionado'. El Diccionario de la Lengua Española (DRAE 2014), s.v. insulto, indica que procede del b. lat. insultus, e incluye en sus dos primeras acepciones: 'acción y efecto de insultar' y desus. 'acometimiento o asalto repentino y violento'.

Es acción verbal ofensiva y sus unidades léxicas pueden representar en sí mismas una carga insultante al evocar conceptos socialmente convenidos para ello. Se considera un comportamiento descortés y, en muchos casos, grosero (Montero 2000: 547563). Enmarcado en su situación comunicativa, es un recurso del hablante cuya fuerza ilocucionaria expresa agresión. Constituyen estas voces una zona especialmente afectiva del lenguaje y muy primitiva puesto que se hallan próximas funcionalmente al grito inarticulado de la ira. Su motivación ofrece una variada gradación que puede responder a los deseos de humillar (herir, despreciar, provocar o estigmatizar), agredir (pelear) o defenderse (protestar, denunciar, desahogarse, rebelarse, burlarse o reírse), entre otros.

Con el fin de contextualizar las imprecaciones en la época -constreñidas por el género al que corresponden-, recordemos que el teatro religioso en el que se integran

\footnotetext{
${ }^{2}$ La edición consultada se encuentra en la Biblioteca Nacional de Madrid, Ms. 14.711 y la referencia es Rouanet, Léo, ed. 1979. Colección de autos, farsas y coloquios del siglo XVI. Hildesheim-New York: Georg Olms (1. a impr., Barcelona-Madrid, 1901). 4 vols.

${ }^{3}$ Reyes Peña matiza las diferencias entre pragmática y semántica: "la pragmática estudia el exceso de significado, el que desborda a la semántica" (Reyes Peña 2003: 23); "La pragmática comparte el interés por la relación entre lenguaje, sociedad y cultura con otras disciplinas del discurso, sobre todo con dos de ellas: la sociolingüística (especialmente la que estudia los procesos de interacción lingüística) y con el análisis de la conversación” (Reyes Peña 2003: 36).

${ }^{4}$ Emplearé insulto, improperio o injuria como sinónimos, aunque pueden establecerse distinciones de matiz: diacrónicamente ofrecen usos diferentes puesto que el primero goza actualmente de empleo general, el segundo es más culto (también significa 'injuria grave de palabra', aunque no suele utilizarse con ese sentido) y el tercero se ha extendido con valor específicamente jurídico (DRAE 2014), s.v. injuria, 4. ${ }^{a}$ acep. Otros términos como ofensa o descalificación también se emplean con el valor general de 'insulto'.
} 
las piezas del $C A V^{\lessgtr}$ es en gran medida oficial e institucionalizado en cuanto promovido y controlado justamente por la autoridad civil y la eclesiástica (Pérez Priego 1988: 3436), y se produce en torno a la fiesta del Corpus Christi. Las distintas obras ${ }^{6}$ vienen a integrarse en un gran drama único que recorre toda la historia de la salvación (Domínguez y Martínez 2012: 11), contienen una proclamación estricta de la doctrina católica más ortodoxa (Pérez Priego 1988: 37), y todas ellas convergen en un punto teológico único que es la exaltación del sacramento de la Eucaristía. En relación con su clasificación temática (Reyes Peña 2003: 394-398), se organizan en siete categorías: bíblicas, bíblico-alegóricas, alegóricas, mariológicas, hagiográficas, histórico-legendarias y profanas. Sus argumentos proceden de las Sagradas Escrituras (Antiguo y Nuevo Testamento), de la hagiografía y de la doctrina católica. Este teatro muestra, asimismo, la lucha contra el protestantismo mediante la propagación de las doctrinas de la ortodoxia católica y el aleccionamiento ${ }^{7}$ en materia religiosa -necesidades manifestadas por el Concilio de Trento- a través de la predicación y el arte.

En cuanto a la consideración religiosa de las ofensas verbales, aunque los autos pertenecen al siglo XVI, los presupuestos doctrinales de la enseńanza cristiana del medievo se mantienen. En este sentido, el insulto en la Edad Media se vincula a la ira y en la Biblia, concretamente en el Libro de los Proverbios, se encuentran entre los siete pecados capitales:

16 Hay seis cosas que el señor aborrece, y siete que le son detestables:

17 los ojos que se enaltecen, la lengua que miente, las manos que derraman sangre inocente,

18 el corazón qué hace aviones perversos, los pies que corren a hacer lo malo,

19 el falso testigo que esparce mentiras, y el que siembra discordia entre hermanos.

Libro de los Proverbios (6:16-19)

\footnotetext{
${ }^{5}$ Reyes Peña (2003: 389-430) indica que el Códice de Autos Viejos está formado por noventa y seis piezas (solo hay una profana, el resto son religiosas) con un total de casi 50.000 versos. Su estudio plantea tres interrogantes en orden a los orígenes del repertorio, la autoría de las piezas y su datación, y considera que esta colección debió de formarse como tal entre 1570 y 1578.

${ }^{6}$ Estas piezas participan en la evolución que se advierte entre 1550 y 1635 en el tratamiento de las fuentes, mediante el progresivo despegue de la traducción literal y el creciente empleo de temas figurativos o accidentales de origen profano, renovados por la alegoría.
}

${ }^{7}$ El drama sacro de la época la corriente moralista excluía toda concesión al humor (Fernández 2013: 187). 
Estos pecados capitales -que dan origen a otras faltas- son una clasificación de los vicios mencionados en las primeras doctrinas del cristianismo cuyo fin es educar a sus seguidores en la moral cristiana. Santo Tomás de Aquino (Suma Teológica, II-II:153:4) los define con las siguientes palabras: "Un vicio capital es aquel que tiene un fin excesivamente deseable, de manera tal que, en su deseo, un hombre comete muchos pecados, todos los cuales se dice son originados en aquel vicio como su fuente principal. [...] Los pecados o vicios capitales son aquellos a los que la naturaleza humana caída está principalmente inclinada".

Los vicios pueden ser catalogados según las virtudes a que se oponen, o también pueden ser referidos a los pecados capitales que la experiencia cristiana ha distinguido siguiendo a san Juan Casiano y a san Gregorio Magno. Dentro de esta tradición cristiana, los siete pecados capitales se contraponen a sus respectivas virtudes:

Cuadro 1. Pecados capitales y virtudes correspondientes

\begin{tabular}{|c|l|}
\hline PECADOS CAPITALES & VIRTUDES \\
\hline Orgullo & Humildad \\
Codicia & Generosidad \\
Lujuria & Castidad \\
*Ira & *Mansedumbre \\
Gula & Templanza \\
Envidia & Amor fraterno \\
Pereza & Diligencia \\
\hline
\end{tabular}

Bien es cierto que la taxonomía que ha llegado hasta nuestros días es la establecida por el mencionado fundador de la escuela tomista, y así el Catecismo de la Iglesia Católica especifica el sentido de la clasificación:

Los vicios pueden ser catalogados según las virtudes a que se oponen, o también pueden ser referidos a los pecados capitales que la experiencia cristiana ha distinguido siguiendo a san Juan Casiano (Conlatio, 5, 2) y a san Gregorio Magno (Moralia in Job, 31, 45, 87). Son llamados capitales porque generan otros pecados, otros vicios. Son la soberbia, la avaricia, la envidia, la ira, la lujuria, la gula, la pereza.

Catecismo de la Iglesia Católica (3. ${ }^{\text {a }}$ parte: La vida en Cristo)

\footnotetext{
${ }^{8}$ 1. a sección: La vocación del hombre: la vida en el espiritu, capítulo $10^{\circ}$ : La dignidad de la persona humana, Artículo 8: El pecado, V. La proliferación del pecado, aptdo. 1866.
} 
Partiendo de la categorización (Casagrande y Vecchio 1991: 173-321)9 de los pecados de la lengua que en la Edad Media establecieron los teólogos, los insultos hallados en los textos estudiados corresponden a la contumelia, la injuria de palabra ${ }^{10}$, que se realiza en presencia del injuriado, el que denuesta designa algún defecto de culpa y se considera injuria grave. Santo Tomás de Aquino apunta diferencias entre contumelia, convicium e improperium:

selon que le contenu de l'insulte est représenté respectivement par une faute, par une peine ou par une situation de minorité ou d'indigence. Exemple : si qualifier quelqu'un de voleur est une insulte, dire qui'il est un aveugle ou un bâtard est un cas de convicium, et lui faire reproche de l'aide apportée en cas de besoin est un improperium (Casagrande y Vecchio 1991: 232).

Las injurias recogidas en los vocablos que conforman el corpus léxico se hallan motivadas por el enfado, si bien se trata de un enojo constreñido por las convenciones literarias.

\section{Corpus analizado}

Del conjunto de las 96 piezas que forman el Códice de Autos Viejos (Reyes Peña 2001: 47), datadas en términos generales entre 1550 y 1575, el corpus seleccionado se halla formado por ocho autos hagiográficos: Auto de Sant Jorge quando mato la serpiente (XXVI), Auto de Sanct Christoval (XXVII), Aucto de un milagro de Sancto Andres (XXVIII), Auto del martyrio de Sant Justo y Pastor (XXIX), Aucto de quando Sancta Elena hallo la cruz de Nuestro Señor (XXXIII), Auto del martyrio de Sancta Barbara (XXXVII), Aucto de Sant Francisco (XXXIX) y Aucto de la visitación de Sant Antonio a Sant Pablo (LXXVI) ${ }^{11}$.

\footnotetext{
${ }^{9}$ Casagrande y Vecchio (1991: 173-321) constituyen una referencia para el estudio de la historia medieval de los pecados: hasta el siglo XIII el discurso sobre los vicios se circunscribía al ámbito monástico; a partir de este momento, se produce una renovación teológica que fija su atención en el mundo de los laicos y vivifica el interés por el sistema de los vicios capitales, de tal forma que se determina la estructura del septenario cuyo momento álgido se extenderá a lo largo del siglo XV. Las autoras, siguiendo las clasificaciones realizadas por los teólogos Pierre le Chantre, Raoul Ardent, Guillaume Peyraut, Jacques de Vitry y Tomás de Aquino, entre otros, recogen blasphemia, murmur, mendacium periurum / falsum testimonium, contentio, maledictum, contumelia / convicium, detractio, iactantia / ironia, derisio, turpiloquium / scurrilitas / stultiloquium, multiloquium, verbum otiusum / vaniloquium y taciturnitas.

${ }^{10}$ Coincide con la clasificación anterior (Chauchadis 2004: 39-45), que ha sido extraída del Manual de confesores $y$ penitentes, de fray Martín de Azpilicueta.

${ }^{11}$ Reyes Peña (2001: 47-48) matiza: "Entonces excluí, igual que hice en un estudio posterior sobre las obras hagiográficas del $C A V$ del que en parte me estoy sirviendo en este, aquellas protagonizadas por figuras neotestamentarias que, por haber alcanzado el reconocimiento eclesial de su santidad (XXV: Aucto de la
} 
Se registran imprecaciones en cuatro de ellos: Auto de Sant Jorge quando mato la serpiente (Reyes Peña 1988: 950), Auto de Sanct Christoval, Auto del martyrio de Sant Justo y Pastor y Auto del martyrio de Sancta Barbara. Las piezas carentes de términos ofensivos muestran situaciones que no propician la tensión requerida para su uso. No se recoge un gran elenco de voces; la propia cultura medieval y el proceso de escrituralización de la lengua lo justifican (Montero 2008: 145); aun con todo, no olvidemos que la lengua del siglo XVI según Ariza "es mucho más rica en variedad de registros que la del XVII" (1998: 217).

El corpus seleccionado ofrece los siguientes vocablos ${ }^{12}$ : animal, cochinuelo, bruto, grosero, salvaje, malvado, mezquino, perverso, desatinado, desdichado, falso, traidor, dañado, maldito, tirano e hi de puta. Teniendo en cuenta que son voces procedentes de un texto literario, la mayoría de los insultos provocados por situaciones de enojo que conducen a la ira $^{13}$-sentimiento no controlado- se hallan atenuados por el decoro exigido en la época y en el género teatral, según se explicará.

\section{LAS OFENSAS VERBALES EN EL ACTO DE COMUNICACIÓN}

El insulto forma parte de la lengua general como un lenguaje no convencional que simboliza valores negativos y es parte de un registro informal (Briz 1996: 15-16). En nuestro corpus la lengua caracteriza las emociones de los interlocutores al proferir el insulto (el dramatismo creado enfatiza y desempeña una función propia del teatro de esta época), si bien el decoro constriñe ciertos usos lingüísticos y la espontaneidad de la conversación, esto es, de la oralidad se encorseta ${ }^{14}$ en el ejercicio que conlleva la transcripción de la misma.

Además de los santos o mártires que son los protagonistas de los autos hagiográficos, predominan los personajes genéricos. En un teatro religioso tiene su explicación puesto que el propósito era entretener al pueblo con el fin de "aprovechar deleitando" (Reyes Peña 2003: 399); estas figuras permitían recrear la función con más acciones, a veces tangenciales, que

conversión de Sant Pablo; XXXV: Aucto de la degollación de Sant Juan Baptista; XLVII: Aucto de la prisión de Sant Pedro; LXIII: Aucto de la conversión de Sant Pablo), podían haber entrado también en la categoría de las hagiográficas, prefiriendo incluirlas entre las piezas bíblicas del Nuevo Testamento, fuente en la que se inspiran sus anónimos autores. Si bien se puede objetar que el San Andrés de la obra núm. XXVIII es uno de los apóstoles y, por lo tanto, un personaje bíblico, al escenificar esta un milagro a él atribuido por fuentes no bíblicas, optamos por catalogarla entre las hagiográficas".

${ }^{12}$ Se transcriben según se recogen en la mencionada edición de Rouanet.

${ }^{13}$ (DRAE 2014), s.v. ira, 'pasión del alma, que causa indignación y enojo'; 'apetito o deseo de venganza'.

${ }^{14}$ La búsqueda de los rasgos lingüísticos de las escenas dialógicas en textos literarios es complicada puesto que la recreación de acontecimientos hablados está adulterada por un "revestimiento de estilización literaria" (Pons 2007: 289-291). Es más, "la historia de los usos lingüísticos es el resultado de una tensión permanente entre oralidad y escritura, que es mutuamente enriquecedora” (Bustos 1995: 18). 
desarrollaban la trama de forma más variada ${ }^{15}$ y respondían a la realidad social o literaria de la época. Algunos de los mártires no pasan desapercibidos por el patetismo que producen las acciones de violencia sobre ellos ejercida y que provoca reacciones diversas (la sumisión absoluta de Bárbara, por ejemplo), y el hecho de que algunos sean niños o adolescentes recrudece más las escenas y las vivifica ante un auditorio que debía adoctrinarse.

En las piezas seleccionadas no son frecuentes las palabras ofensivas ${ }^{16}$, si bien la tragedia que se vive en algunas despierta en el receptor una expectación aún mayor ante la insólita peripecia escenificada, que justifica el uso de las mismas. No abundan los denuestos medievales (Castillo Lluch 2004: 27) porque son de carácter marcadamente oral y se evitan en géneros escripturales con un estatus formal, como la prosa histórica, la prosa jurídica y también los textos literarios anteriores al siglo $\mathrm{XV}^{17}$; en cambio, en los fueros se aluden de modo explícito como vedadas determinadas voces (atañen generalmente al cuerpo -sexualidad y enfermedad- y a la moral del individuo) que son faltas que alteran el orden social. A partir del siglo XV se constatan más registros en literatura y así La Celestina ofrece buena muestra de ello ${ }^{18}$.

Los vocablos ofensivos que conforman el corpus se contextualizan en el momento en el que se desarrolla el acto de habla con el fin de explicar sus motivaciones, valores expresivos y funciones lingüísticas (Jakobson 1975).

\subsection{Auto de Sant Jorge quando mato la serpiente (XXVI)}

La infanta ha huido al campo, está desesperada y rompe en llanto. El pastor la oye y le exige silencio porque así evita atraer a la sierpe y que devore su ganado. Esta recriminación enciende la ira de la futura mártir, que replica tildando de grosero al pastor. Se siente profundamente enojada porque conoce su destino fatal ya que su padre la va a entregar al dragón como pasto (más tarde aparecerá San Jorge y la joven le contará sus cuitas). Se trata, por tanto, de un insulto que responde a una defensa personal y se advierte como protesta ante lo que ella considera injusto o molesto, y cuyas funciones son la apelativa y la expresiva:

\footnotetext{
${ }^{15}$ Las paremias en este teatro catequístico constituyen un uso lingüístico que permite que la representación resulte más amena y directa (Rodríguez 2011: 137).

${ }^{16}$ El género textual jurídico no es el marco más adecuado para analizar la oralidad, si bien ofrece palabras vedadas en declaraciones de imputados y testigos en los procesos inquisitoriales: gafo, fodido, fijo de fodido, cornudo, etc. (Montero 2007: 391-400).

${ }^{17}$ Principalmente los fueros aportan información directa sobre voces prohibidas de la lengua medieval (Castillo Lluch 2006: 2698).

${ }^{18}$ Una forma de expresión de la cultura popular cómica se manifiesta en un amplio vocabulario familiar y público caracterizado por el uso frecuente de groserías o palabras injuriosas (Bajtin 1995: 20-22).
} 
Ynfanta: Calla, déjame, grosero;

no me enojes, por tu vida:

solo aqueso es lo que espero,

que ya la vida no quiero,

pues por fuerça fui traida. (166)

\subsection{Auto de Sanct Christoval (XXVII)}

Un presuntuoso hidalgo portugués se lamenta de sus desventuras, ha crecido el río y no puede cruzarlo. Se presenta como un personaje simple -es el tipo cómico que agrada y divierte al auditorio- que se desahoga ante su propio infortunio y emplea el "falso denuesto" con fines humorísticos y expresivos:

\section{Portugués: O fidalgo desdichado! canta fortuna me vino en morirse meo cavallo! O can crescido va el vado! O traballoso camino! (306)}

\subsection{Auto del martyrio de Sant Justo y Pastor (XXIX)}

Los niños Justo y Pastor, conscientes de su final, responden al maestresala quien los matará por no adorar a Marte. Ellos se defienden en tono de protesta, expresan sus sentimientos y emplean palabras con fuerte valor emotivo y apelativo:

Justo: Malditto sienpre tu seas, salvaje y bruto animal, pues en un dios tan bestial oses afirmar que creas, dejando a Dios eternal. (306)

Pastor: Perdido, loco de ti, desatinado y malditto, dejas a Dios ynfinito que rrije y govierna a ti por subjetarte a un maldito? (316)

El pregonero anuncia que van a morir y el maestresala aviva la angustia de los niños, desea humillarlos y herirlos verbalmente: 
Maestresala: Sus, mueran los malhechores, perversos, falsos, malvados! (371)

Los conducen a su trágico final, Pastor trata de defenderse y se rebela con un improperio con valor apelativo que apela a la falta de justicia y denuncia el abuso de poder del que son víctimas:

Pastor: Donde nos llevais, tiranos? (384)

Justo se reafirma en su fe y ensalza a Cristo, el pregonero se muestra airado y lo zahiere con expresivas imprecaciones:

Pregonero: que donoso cochinuelo!

O hi de puta traidor! (416)

Ante la muerte inminente, también Pastor reafirma su fe y esto provoca el enfado del maestresala quien con sus despectivas palabras alude a la condena que les espera:

Maestresala: O falsos y muy dañados! (461)

\subsection{Auto del martyrio de Sancta Barbara (XXXVII)}

Hay que destacar en esta pieza la dulzura de la mártir, no profiere palabras ofensivas aun siendo consciente de que la muerte la aguarda; es más, se produce un contraste -edificante y purificador para el espectador- en el momento final puesto que Bárbara ofrece doble sumisión: ante la injusticia de la sociedad y ante la muerte que le inflige su padre, implacable verdugo. Tal acatamiento -y bondad implícita- engrandece a la santa ante tan horrendo filicidio ${ }^{19}$. Por otro lado, y en relación con la doctrina cristiana, el pecado de la ira se torna en virtud que corresponde a la mansedumbre mostrada por ella.

Veamos los momentos en los que se registran las ofensas: ante las intenciones de Dióscoro, Bárbara confiesa a su padre que está desposada con Jesucristo, esta revelación produce angustia y enfado en su progenitor, quien lanza improperios con valor expresivo y apelativo:

Dioscoro: O que crecido dolor!

$\mathrm{Di}$, quien dizes qu'es, traidora?

\footnotetext{
${ }^{19}$ En la brevísima Farsa de sancta Bárbara destaca la presencia muda de la santa que interviene únicamente hacia el final del diálogo con una sola réplica de ocho versos (Cazal 2004: 85-97).
} 
Barbara: Jesuxpo mi señor.

Dios y honbre, salvador

que dentro en mi alma mora, (181)

Dioscoro: O traidora! muera, muera!

No te cale que solapes

tu maldad, qu'es clara y vera.

A, bachillera, espera!

no ayas miedo que te escapes. (186)

Solo se aprecia una situación en que Bárbara se muestra muy enojada y no deja de sorprender el giro ${ }^{20}$ que experimenta su generalizada sumisión. Ella sale huyendo y el segundo pastor le indica a Dióscoro que sabe dónde puede estar escondida, la joven lo oye y lanza una "maldición":

\author{
Barbara: Rruego a mi Dios y Señor \\ que aqueste que me a ynjuriado \\ le castigue de tenor \\ que muera de mal dolor \\ el y todo su ganado. (226)
}

Bárbara reafirma su creencia y argumenta constantemente a su favor, esta situación provoca la ira del adelantado (quien no oculta la importancia que da al físico de la mártir, aspecto que acrecienta la tensión del espectador), quien le responde de forma expresiva y henchida de desprecio:

${ }^{20}$ Un cambio similar de registro se produce en el Aucto de la degollacion de Sant Juan Baptista (XXXV) que, como sabemos, no pertenece al grupo de los hagiográficos sino al de los bíblicos (seguimos la clasificación de Reyes del Nuevo Testamento, sin referencias eucarísticas, Reyes Peńa 2003: 396). Tomando parte del argumento y para contextualizar, el rey quiere poseer a Herodías, la mujer de su hermano, y lo hará puesto que es quien tiene el poder. Ante la pregunta que le formula a Cornelio sobre lo que se dice de él, este le explica que lo consideran un tirano Entra San Juan, quien juzga inadecuada esa intención y se enfrenta a él con estas palabras:

Dime, bestia ynsaziable, generacion de serpiente, di, Tetrarca abominable, la tierra como consiente tu vicio tan detestable?

Qual rrey divino y humano

te dieron autoridad

para que como tirano

tu cometieses maldad

con la muger de tu hermano? (36) 


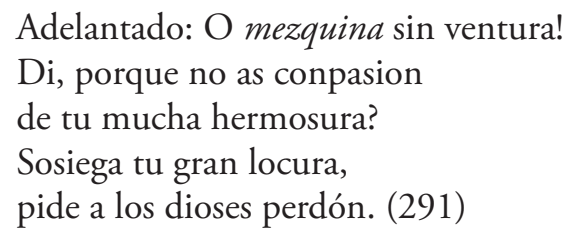

Las funciones del lenguaje en sus diversas situaciones comunicativas más utilizadas son la conativa o apelativa junto con la expresiva o emotiva: el hablante manifiesta con el insulto directo su enojo y causa una reacción en el auditorio que se halla expectante ante la tensa situación dramatizada. La condición de verdad queda relegada a un segundo plano y es el efecto producido en el interlocutor lo que realmente destaca.

\section{ESTUdiO LÉXICO-SEMÁNTICO DE LAS OFENSAS VERBALES}

El análisis realizado muestra que los insultos se utilizan en contextos de iracundia o enojo $^{21}$, la relación personal -en la mayoría de los casos jerárquica- no resulta un obstáculo para su empleo porque la situación provoca el uso de estas palabras que acrecientan la tensión y expectación necesarias para que el auditorio perciba las escenas de manera vívida. Responden a un recurso propio del hablante cuya fuerza ilocucionaria se expresa como agresión en diferentes grados y la acción verbal, reflejada en una palabra o interjección impropia, representa en sí misma una carga negativa al evocar conceptos socialmente convenidos para ello. Se transgreden, en cierta forma, las normas de cortesía y se aprecia un intento de aproximación al habla viva que se encuentra encorsetada por la transcripción textual. Responden los improperios a la descalificación referente por lo general a la calidad moral, concretamente en situación de defensa, humillación o enfado.

El léxico referido al insulto no siempre aparece marcado lingüísticamente en los repertorios consultados (a veces se clasifica como malsonante o coloquial). Las ofensas verbales del corpus se profieren en situación dialógica con el "adversario", esto es, son insultos directos. El núcleo monosémico de las malas palabras es el de la referencia al concepto y este se determina por normas externas, pero esta función primigenia queda desvaída en ciertos improperios cuya función conativa asume mayor relieve puesto que el hablante profiere el insulto directamente contra su interlocutor avivando su enfado ${ }^{22}$.

Los procedimientos lingüísticos empleados en los denuestos responden a recursos morfológicos (sufijación de cochinuelo con valor despectivo); también se emplean medios sintácticos, como la combinación o creación de unidades fraseológicas (en algunos casos acuñadas, como la interjección impropia hi de puta; y en otros con implementación adverbial, muy dañados); y, asimismo, se aprecian recursos semánticos basados en desplazamientos de significado que crean metáforas ya fijadas en la historia de la lengua (animal).

\footnotetext{
${ }^{21}$ Excepto el proferido por el fidalgo y dirigido a sí mismo (auto XXVII).

${ }^{22}$ Es importante diferenciar entre improperios ofensivos y humorísticos (Ugarte 2011: 137-158).
} 
El campo conceptual que conforma el insulto se descompone en subclases que aluden a aspectos negativos de la persona injuriada y permiten organizar las voces en esferas conceptuales (Baldinger 1977) ${ }^{23}$ a partir de los semas comunes -no siempre fáciles de clasificar porque en algunos casos ofrecen concomitancias con otros apartados-. En la siguiente tabla se muestran los rasgos que comparten los términos y que se organizan en esferas conceptuales que responden a irracionalidad, rudeza o grosería, maldad, despropósito, fingimiento o traición, condena divina, abuso de poder y alusión familiar.

Cuadro 2. Esferas conceptuales de las ofensas verbales

\begin{tabular}{|l|l|}
\hline \multicolumn{1}{|c|}{ ESFERAS CONCEPTUALES } & \multicolumn{1}{c|}{ OFENSAS VERBALES } \\
\hline IRRACIONALIDAD & animal, cochinuelo \\
\hline RUDEZA O GROSERÍA & bruto, grosero, salvaje \\
\hline MALDAD & malvado, mezquino, perverso \\
\hline DESPROPÓSITO & desatinado, desdichado \\
\hline FINGIMIENTO O TRAICIÓN & falso, traidor \\
\hline CONDENA DIVINA & dañado, maldito \\
\hline ABUSO DE PODER & tirano \\
\hline ALUSIÓN FAMILIAR & hi de puta \\
\hline
\end{tabular}

\subsection{Irracionalidad}

Este primer grupo recoge las voces que comparten el sema 'falto de raciocinio', esto es, hombre que se ha convertido por sus actos en un ser alejado de su esencia diferenciadora (la razón) y se aproxima al animal como ser irracional por antonomasia. La metáfora zoomorfa animal es pronunciada por los mártires; en cambio, cochinuelo lo utiliza el pregonero para referirse al pequeño Justo, aludiendo al sentido despectivo 'ser pequeño y repugnante'. Quienes más insultan son los verdugos, en este caso, y no sus víctimas, modelos de resignación cristiana. Veamos los términos:

\subsubsection{Animal}

El uso de este improperio como adjetivo y con los sentidos de 'irracional' y 'de comportamiento instintivo' se documenta en la Edad Media y responde al empleado en el

${ }^{23}$ Tomamos los conceptos esfera semántica y sema sin el objetivo de aplicar su teoría semántica estructural (sintagmática y paradigmática). 
corpus. Animal se usaba (Corominas y Pascual DCECH 1993) como adjetivo, s.v. alma ${ }^{24}$, hacia 1560 (P. de las Casas) y también se recoge en los siglos XIV y XV con el sentido de 'irracional en oposición al hombre' (Alonso 1986). El lexicógrafo toledano (Covarrubias ed. 2006) matiza el sentido "se dice del bruto y es nombre genérico para él y para el hombre; pero vulgarmente solemos decir animal al hombre de poco discurso".

Las siguientes obras coinciden en la calificación otorgada e incluyen el sema grosería: NTLLE25 (Academia 1726), 'se llama por injuria a un hombre grosero, tosco, torpe e incapaz', y el Diccionario de la Lengua Española (DRAE 2014), en la tercera acepción alude a la negativa actitud del hombre, esto es, 'persona de comportamiento instintivo, ignorante y grosera'.

\subsubsection{Cochinuelo}

En los diccionarios consultados destaca el valor físico del improperio, si bien en el corpus hace alusión a la repugnancia en sentido moral. En literatura, cochino (Corominas y Pascual $D C E C H$ 1993) se refería al hombre sucio, especialmente al que ha eructado. Se registra metafóricamente, s.v. cochino, con el sentido de 'puerco' en los siglos XIV y XV (Alonso 1986). También se recoge (Covarrubias ed. 2006) como alusión al aspecto físico y al comportamiento (primera coincidencia con el sentido del corpus), s.v. cochino, 'Al hombre sucio, o de mal trato, decimos que es un cochino'. Se trata de un insulto referido a la condición física (o moral), que en la Edad Media aparecía junto con otros como hediondo, tiñoso, tocino... (Tabernero 2013: 143-161).

Se registra en sentido recto (Nieto y Alvar 2007), s.v. cochino; y también con traslación semántica (Academia 1729), 'metafóricamente se llama así a la persona que es desaliñada, asquerosa o puerca'. En la actualidad (DRAE 2014), s.v. cochino, las diversas acepciones recogen la marca de registro coloquial: 3 . $^{\text {' }}$ 'sucio, desaseado o asqueroso', 4. ${ }^{a}$ 'despreciable, miserable o ruin', y 5. a 'grosero o indecente'. Estas dos últimas se hallan más próximas a las del corpus.

En cuanto al sufijo -uelo (González Ollé 1962: 281-284), los diminutivos aparecen ya en el Glosario de El Escorial, en el Libre dels tres Reys d'Orient y en Berceo (moçuelo). En el español antiguo ofrece un uso muy restringido pues solo afecta a las palabras acabadas en -ero (>-a r i u) o cuyo radical termina en vocal o en -z, -ç, -ch, -ñ y -j (y). El sufijo es usual entre los árabes españoles. En el siglo XV se registran voces como mostazuela (Enzina), bermejuelos (Montesino), cabę̧uelas (Jorge Manrique), etc.

\footnotetext{
${ }^{24}$ Solo cuando el término no coincide con el lema del diccionario o vocabulario cotejado, esto es, con la voz del corpus, se especifica el nuevo vocablo antecedido por "s.v.".

${ }^{25}$ Todas las citas del diccionario en la que se incluye el término Academia, ante el año correspondiente, proceden del Nuevo Tesoro Lexicográfico de la Lengua Española [NTLLE].
} 


\subsection{Rudeza o grosería}

Este segundo grupo engloba los términos que destacan cualidades negativas del hombre en sus actuaciones rudas, faltas de modales y poco corteses; actitudes que también comparten semas con la esfera conceptual anterior puesto que en algunos casos acercan el hombre al animal. Se mantienen los sentidos etimológicos destacados cuyos semas aluden a 'rudeza de entendimiento y de modales'. Los tres términos registrados son proferidos por los mártires que ponen de relieve la exagerada carencia de miramiento de sus ejecutores. Los vocablos son los siguientes:

\subsubsection{Bruto}

Se recogen dos primeras acepciones (Alonso 1986) atribuidas al hombre: 'rudo de entendimiento' y 'de costumbres brutales y torpes'; y la tercera, al animal: 'irracional, entendiéndose comúnmente de los cuadrúpedos, y en especial del caballo' ( $\mathrm{S}$. XV). Se relaciona, asimismo, con la parquedad en palabras y la ausencia de buenos modales (Covarrubias ed. 2006), 'De do vino llamar brutos a los hombres de poco discurso y groseros'. Actualmente (DRAE 2014), 3. ${ }^{\mathrm{a}}$ acep., el sentido se aproxima a la acepción del corpus: 'violento, rudo, carente de miramiento y civilidad'. Coincide, por tanto, el valor semántico con el utilizado en el auto ('de modales rudos') y proferido por el nińo Justo ante las amenazas de muerte del maestresala.

\subsubsection{Grosero}

Se registra en Universal Vocabulario, 1490 (Corominas y Pascual DCECH 1993) bajo el lema grueso (s.v.). Ya en el siglo XV (Alonso 1986) significaba 'basto, grueso, ordinario y sin arte'. También se recogen (Covarrubias ed. 2006) sentidos alusivos al comportamiento y a la falta de conocimiento o raciocinio (es el caso del corpus): 'vale tanto como rústico, poco cortesano, cuando se dice del hombre o de su razonar y conversar'. Se remite (Nieto y Alvar 2007) el término a agreste (PALENCIA) y, de esta forma, se pone en común con los semas destacados. En el siglo XVIII (Academia 1780) ofrece un valor similar al de Covarrubias, 'descortés, y que no observa urbanidad ni política', que coincide, a su vez, con la 2.a acep. del Diccionario de la Lengua (DRAE 2014), 'descortés, que no observa decoro ni urbanidad'. Recordemos que la infanta llama grosero al pastor que la molesta y considera que esa actitud es una descortesía; se mantiene así el sentido 'descortés' y, por tanto, 'molesto'.

\subsubsection{Salvaje}

Occitanismo, etimológicamente 'propio del bosque', documentado en Juan Ruiz (Corominas y Pascual DCECH 1993), s.v. selva. Asimismo, se registra (Alonso 1986) como adj. fig. (siglos XIV y XV) con el sentido 'sumamente necio, hurańo, terco, zafio o 
rudo', semas coincidentes con el corpus. También se consideran (Covarrubias ed. 2006) las cualidades sociales, 'villano que sabe poco de cortesía'. Se recoge (Nieto y Alvar 2007) su valor etimológico en 'saluaje o syluestre, es montesino', ARRAGEL 1433. Por otro lado, se destacan (Academia 1832) semas relacionados con la falta de entendimiento y se define con idénticas palabras que Alonso. Un nuevo matiz se ofrece (DRAE 2014) en la 7. a acepción con marca de registro coloquial, 'cruel'. En el Auto del martyrio de Sant Justo y Pastor, Justo considera una tropelía la intención que el maestresala muestra puesto que lo matará por no adorar a Marte y lo califica con el sentido que adquiere en la Edad Media.

\subsection{Maldad ${ }^{26}$}

Son apelativos que comparten el sema 'malo' con diferentes grados o matices específicos que responden, por lo general, a su valor etimológico y que se mantienen en la actualidad (boca sin bondad, cruel, malvado, mezquino y perverso). En perverso se aprecia un grado más intenso de maldad (lo profiere el maestresala para dirigirse al nińo Justo). Mezquino también ofrece un estado negativo más marcado y es injuria proferida por el adelantado para calificar a santa Bárbara.

\subsubsection{Malvado}

Procede del lat. vg. malifatius 'malhadado, desgraciado' y la primera documentación es de Berceo: oriella malvaza 'viento maligno' (Corominas y Pascual DCECH 1993). En castellano antiguo es menos frecuente que en catalán y galorrománico. También se recoge en Fuero de Sepúlveda (S. XIII), en el glosario del Escorial (h. 1400), en APalc. ("impiatus... se dize por ombre de malvadas fazańas”), aparece una vez en el léxico noble de Don Quijote, y Autoridades cita un ejemplo del XVII. En el Siglo de Oro es palabra ya generalmente usada, principalmente en función de sustantivo. También se registra (Alonso 1986) en los siglos XIII al XV con sentidos que comparten semas del corpus: 'muy malo, perverso', 'corrompido' ('corruptus' en Nebrija ed. 1989) y 'malo'. Posee grado superlativo la acepción 'el que es por extremo malo' (Covarrubias ed. 2006, y Nieto y Alvar 2007), y se recogen nuevos matices (Academia 1734) en la definición 'insolente, vicioso, mal inclinado y perdido'.

El sentido actual (DRAE 2014), 'dicho de una persona: Muy mala, perversa, mal inclinada', ya está registrado en la Edad Media y en el corpus. Es, por tanto, un término ampliamente documentado y cuya acepción ('malo en extremo') responde a la utilizada por el maestresala para dirigirse con rabia a los que no profesan su religión.

\footnotetext{
${ }^{26}$ Se recogen en documentos del Archivo Histórico Nacional (sección Inquisición) fechados entre 1620 y 1655 interesantes términos que pertenecen al dominio de la maldad, como son bellaco, desperjurado, infame, mal nacido, matamaridos, picaro y ruin (Tabernero 2011: 101-122).
} 


\subsubsection{Mezquino}

Este arabismo (Corominas y Pascual DCECH 1993) procede de miskin 'carente

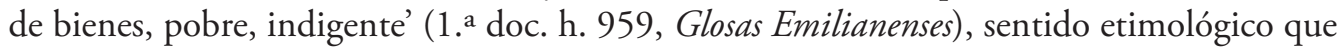
pronto pasa a 'desgraciado, miserable' (en Disputa: “mezquino, mal fadado, ¡ta mal ora fuest nado!", Ariza 1983: 62), según traslación semántica -entendemos- originada por la situación derivada de la ausencia de sustento. En APalc. se indica "infelix es desdichado y mesquino, que carece de toda buena ventura". La acep. moderna 'escaso, miserable, avariento' se documenta por lo menos desde mediados del siglo XVI, en el Lazarillo (Aut.) y es la normal desde el Siglo de Oro. Este término pertenece al lenguaje clásico y vulgar al mismo tiempo, y en España muestra ya tendencia a la evolución semántica que sufrió en romance. Se recoge (Alonso 1986) en la 4. ${ }^{a}$ acep. (S. XIII) con el sentido de 'miserable, desdichado, infeliz'.

Una interesante nota etimológica y social (Covarrubias ed. 2006) se aprecia en el siguiente comentario: "Introdújose este nombre entre los árabes para sinificar el pobre que por su flaqueza y debilidad no podía trabajar, y así le era forzoso quedarse quedo y vivir de limosna”. También se hace alusión a la situación de indigencia (Nieto y Alvar 2007), "algunas veces se toma por el hombre miserable y apretado que, teniendo para sí, y aun para los otros, no osa comer y vive con gran miseria". Se amplía (Academia 1734) en su segundo lema la esfera semántica -comportamiento-, léase, 'significa también miserable, escaso y apocado'. El uso actual (DRAE 2014) ofrece dos acepciones relacionadas con la actitud, esto es, 2. a acep. 'falto de nobleza de espíritu' y 6.a acep. desus. 'desdichado, desgraciado, infeliz'. En el texto es una injuria proferida por el adelantado a santa Bárbara y puede entenderse como 'desdichado' o 'falto de nobleza de espíritu'. Es reseñable el cambio semántico de mezquino, cuyo significado etimológico 'carente de bienes, pobre' evoluciona en romance y ofrece el sentido más utilizado actualmente 'que escatima en el gasto'.

\subsubsection{Perverso $0^{27}$}

Se registra (s.v. verter) en Autoridades (Corominas y Pascual DCECH 1993) y en idéntica centuria (Alonso 1986) con el sentido de 'sumamente malo, depravado en las costumbres u obligaciones de su estado', que responde al sentido del corpus y que se repetirá,

${ }^{27} \mathrm{El}$ siguiente fragmento (CORDE) ofrece un ejemplo del sentido dado a perverso:

Como el enperador ordenase las eglesias, las quales el muy malo Cosdroe derribara \& de sus propias espensas las mandase reparar, luego despues de su partida, un prinçipe de los arabes llamado Homar, recogida consigo infinita muchedunbre de conpannas, asi poderosamente como quebrantando enemigablemente, entro la Tierra Santa e a poco de tienpo non solamente pervaleçio \& pudo mas que los cristianos que en el reino de Gerusalen moravan, mas aun todas las çibdades, desde Laodiçia de Siria fasta en Egipto \& asi mesmo Damasco con muchas otras çibdades, con mucho derramamiento de sangre, la cruel bestia las tomo. E aqueste muy cruel Homar era diçiplo del porfioso \& muy perverso Mahomad \& el terçero suçesor de su reino (Anónimo Traducción de la "Historia de Jerusalem abreviada" de Jacobo de Vitriaco 2000: 2, 1350). 
con diversos matices o grados, en la historia de la lengua. Similares acepciones apreciamos en 'el depravado' (Covarrubias ed. 2006), y en 'es también una manera de malvado hombre', ARRAGEL 1433 (Nieto y Alvar 2007). Destaca el grado superlativo: 'sumamente malo, defectuoso en su línea, depravado en las costumbres u obligaciones de su estado' (Academia 1737), que coincide con el uso actual (DRAE 2014), 'sumamente malo, que causa daño intencionadamente', sentido etimológico registrado en el auto estudiado.

\subsection{Despropósito}

Estas voces inciden en el desatino cometido y el resultado que tal acción conlleva.

\subsubsection{Desatinado}

Voz recogida (s.v. tino) en Celestina (Corominas y Pascual DCECH 1993) y en Nuevo Tesoro (HORNKENS 1599), en este con el sentido 'alocado, necio, rabioso' (Nieto y Alvar 2007). También con el valor de 'desarreglado, sin tino' (siglo XV) junto con el verbo, s.v. desatinar, 'hacer perder el tino, atolondrar' (Alonso 1986). Los siguientes registros recogen las acepciones del corpus: 'vale también decir o hacer desatinos y despropósitos' (Academia 1732), s.v. desatinar, y en $2 .^{a}$ acep. 'que habla o procede sin juicio sin razón' (DRAE 2014).

\subsubsection{Desdichado}

Coincide el sentido registrado en el auto, esto es, el etimológico 'desgraciado' en los compendios léxicos estudiados. Se recoge el derivado desdichado (s.v. dicha, 'suerte feliz') en 1505, APalc. (Corominas y Pascual DCECH 1993), esto es, 'falto de suerte o felicidad'. Un valor registrado y más preciso (Alonso 1986) es el mencionado 'desgraciado, infeliz, desafortunado' (siglos XIV y XV), significado que converge (Covarrubias ed. 2006) con desdichado, 'el poco afortunado' (s.v. desdicha); con 'infeliz' (Nebrija ed. 1989) y con 'desuenturado, malheureux' (Nieto y Alvar 2007). Se recoge otro matiz del término (Academia 1732): 'es un desdichado, frase vulgar con que se da a entender que para alguno es poco hombre sano y de bondad'. Este hispanismo muestra actualmente el mismo sentido etimológico (DRAE 2014), esto es, 'desgraciado', registrado en el corpus.

\subsection{Fingimiento o traición}

Las injurias de este grupo son proferidas por el maestresala (designa como falso al pequeño Pastor antes de que muera) y Dióscoro (llama traidora a la joven Bárbara cuando se declara seguidora de Cristo). El insulto traidor abarca los planos religioso y moral: la traición contra la religión que profesa la mártir y la traición contra el verdugo por hacer caso omiso de sus reiterados requerimientos. 


\subsubsection{Falso}

Participio pasivo de fallère 'engañar', y vocablo frecuente y popular en todas las épocas del idioma. La conservación de la $f$ y del grupo al indica que prevaleció la pronunciación de las clases cultas, a causa del frecuente empleo en apreciaciones morales, emitidas sobre todo por el clero y los elementos más instruidos (Corominas y Pascual DCECH 1993).

En los siguientes vocabularios viene a coincidir el sentido general 'engañoso' (en el auto alude a 'contrario a la verdad, a la ley'). Se aprecian tres acepciones (Alonso 1986): 'engañoso, fingido, simulado' (siglos XII al XV); 'incierto y contrario a la verdad' (S. XIV); y 'falsario, embustero' (S. XIV). Los vocabularios citados a continuación muestran similar significado: (Nieto y Alvar 2007), 'mentiroso, artero, que con malas artes contiende engañar' (PALENCIA 1490); (Academia 1732), 'engañoso, fingido, simulado, falto de ley o realidad'; y (DRAE 2014) en 1. a acepción 'fingido o simulado', si bien en la 12. a acep. añade la marca germ. 'verdugo que ajusticia a los reos'. En el corpus se mantiene, según se ha indicado, el valor etimológico.

\subsubsection{Traidor}

La palabra latina tradere 'entregar' es derivada de dare (Corominas y Pascual $D C E C H$ 1993), s.v. dar, de ahí el cast. antiguo traer 'traicionar' (fin siglo XIII, Primera Crónica General: "trayor e omne malo..."). El término se registra con el sentido 'que comete traición' (Alonso 1986 y DRAE 2014). Más preciso es 'traydor a su tierra, o el que mata a su padre, como matricida', SANTAELLA 1499 (Nieto y Alvar 2007). Se recoge en el segundo lema (Academia 1739) una acepción más amplia, 'por extensión se aplica a los irracionales, que faltan a la obediencia, enseñanza o lealtad debida a sus dueños: como caballo traidor o perro'.

En los siglos bajomedievales, la violencia verbal operaba sobre los códigos del honor que cada uno de los grupos había sido capaz de forjar y se nutría de la reputación del injuriado. La injuria de traidor era la más frecuente en la práctica jurídica y se vinculaba a la importancia otorgada por todos los sectores de la población a la fidelidad y el compromiso, y también podía responder al quebrantamiento de la fidelidad obligada a la Corona. La traición ${ }^{28}$ se considera inherente a los judíos y a los musulmanes (hay conocidos ejemplos literarios). Los términos traydor, alevoso, falso, periurado, así como las acusaciones injuriosas de haber mentido, hacen referencia a la infidelidad al señor y a la fe jurada, a la paz, a la

\footnotetext{
${ }^{28}$ Se han recogido numerosos calificativos que recibieron judíos y moros durante la Edad Media. Los términos se prestan a doble empleo. Si se injuria a alguien tratándolo de judio o de moro cuando no lo es, o si un cristiano usa el denuesto tornadizo, es toda la trama imaginaria de estas identidades la que sostiene la injuria. Los judíos y moros son denigrados con las formulaciones que hacen a la construcción cristiana de sus identidades: denostadores, alusiones al color negro, a la lujuria y homosexualidad, a la traición... (Madero 1992: 119-136).
} 
tregua, pero también a otros deberes familiares, a la amistad, a las solidaridades de clase (Usunáriz 2013: 281) y a la mentira (Ariza 2008: 73-80) como traición a la verdad. La traición se encarna en aquellos personajes que fueron los terrores de la Edad Media: el Diablo, los infieles y los heréticos. La lealtad y la traición son concebidas como identidades familiares. En el corpus el sentido etimológico se contamina del valor social 'traidor a la religión'.

\subsection{Condena divina}

Las ofensas aquí contenidas se refieren a la actitud mostrada contra la religión y por la que se sufrirá el castigo correspondiente, esto es, la persona que así actúa será condenada y considerada impía.

\subsubsection{Dañado}

Del latín damnare 'condenar'; dañar (s.v. daño) en la acep. 'causar daño' es innovación del portugués y del castellano, se registra en la Edad Media y aun en el siglo XVI (Corominas y Pascual DCECH 1993). Se recoge un matiz religioso (s.v. damnado) en el sentido 'condenado, réprobo', en el S. XIII (Alonso 1986). Menos preciso es el sentido 'dañado, endommagé, gasté, desgasté, corrompu, incommodé, OUDIN 1607 (Nieto y Alvar 2007). Un interesante valor aporta (Academia 1732) esta apreciación 'se llaman también a los condenados a las penas del infierno, pero en este sentido tiene hoy muy poco uso'. En el auto estudiado, se dirige el maestresala a Justo y Pastor -están sentenciados a priori- y los califica como dañados 'condenados', esto es, en sentido etimológico (no empleado en la actualidad), frente al actual (DRAE 2014), 'malo, perverso'.

\subsubsection{Maldito}

Maldecir (s.v. decir) se recoge en Disputa, hacia 1200 (Corominas y Pascual DCECH 1993), y el participio (Oesl., s.v. maldito) en Serrano, 1202. Se registra con el sentido de 'maldito' (Alonso 1986), s. vv. maldicto, maldicho. Se añade el valor relacionado con la religión en 'maldito o maluado, sacrilegus, impius', BARR. 1570 (Nieto y Alvar 2007). Se alude en el segundo lema (Academia 1734) a actitudes depravadas, 'significa también perverso, malvado, de mala intención y dañadas costumbres', si bien la tercera entrada ofrece un matiz referido a la condena divina, 'se toma también por el condenado y castigado por la Justicia Divina'.

Actualmente (DRAE 2014) destacan tres acepciones: 'perverso, de mala intención y dañadas costumbres', 'condenado y castigado por la justicia divina' y 'de mala calidad, ruin, miserable'. Maldito -con el sentido de 'impío'- es el insulto que Pastor profiere al maestresala, bien podría considerarse que mantiene en parte su valor etimológico 'perverso' (en este caso ofrece semas comunes a la esfera semántica de la maldad). 


\subsection{Abuso de poder}

Pastor utiliza tirano contra su opresor. Ejercer mal un cargo público ${ }^{29}$ es una falta que tiene una consideración social condenable.

\subsubsection{Tirano}

Se registra con el sentido de 'reyezuelo, soberano local' y 'tirano, déspota' (Corominas y Pascual DCECH 1993), similar definición se recoge en el siglo XV, 'que abusa de su poder, déspota' (Alonso 1986). Matiz parecido (Covarrubias ed. 2006) ofrece la definición 'llamamos tirano comúnmente cualquiera que, con violencia, sin razón ni justicia se sale con hacer su voluntad'. Se añade nuevo sema: 'se llama al varón o príncipe que es desordenado, codicioso [...]', ARRAGEL 1433 (Nieto y Alvar 2007), y 'entre los antiguos se decía por rey [...] es tirano el rey que vive sin cierta ley o el que por fuerza violenta usurpa el señorío y es señor cruel', PALENCIA 1490. Esta segunda acepción es similar a 'se aplica al señor que gobierna sin justicia' (Academia 1780) y a 'dicho de una persona: Que abusa de su poder, superioridad o fuerza en cualquier concepto o materia, y también simplemente del que impone ese poder y superioridad en grado extraordinario' (DRAE 2014), 2. a acep. Se aprecia que el sentido etimológico apenas ha sufrido cambios.

\subsection{Alusión familiar}

Justo se reafirma en su fe y ensalza a Cristo, el pregonero se muestra airado y le llama hi de puta, utilizadísimo y malsonante improperio. Aunque haya perdido relieve su valor referencial, pocas veces se desvincula plenamente de su sentido literal a no ser que se trate de una interjección puramente enfática.

\subsubsection{Hi de puta}

Primer registro (s.v. puta) en Berceo (Milagros, putaña); en el siglo XV abundaba en literatura, aunque lo evitaba la conversación decente (Corominas y Pascual DCECH 1993). Encontramos puta (s.v.) con el mismo sentido (Alonso 1986) que 'ramera' en el siglo S. XIII; y en 'la ramera o ruin mujer' (Covarrubias ed. 2006). El sentido literal también se recoge en hijo de puta (s.v. hijo), 'bastardo' (Nieto y Alvar 2007) y en 'el que no es procreado de legítimo matrimonio’ (Academia 1734). Se aprecia, asimismo, como insulto e interjección enfática con los siguientes sentidos: 'lo mismo que hijo: y siempre parece se usaba para denostar o reprehender a alguno; assi se decía regularmente $H i$ de puta, Hi de ruin; pero ya no tiene uso' (Academia 1734), s.v. hi; y 'algunas veces se dice esta expresión

\footnotetext{
${ }^{29}$ En el Auto de Navaly de Abigail (LIX) se recoge el sintagma cruel tirano para contraponerlo a un rey escrupuloso, razonable, pacífico y de renombre.
} 
sin que denote injuria o denuesto, sino se usa de ella como admirándose, y entonces es interjección que alaba alguna cosa' (Academia 1734), s.v. hi de puta. Autoridades distingue el sintagma completo hijo de puta 'bastardo', frente a la forma apocopada hi de puta con el uso interjectivo indicado. El empleo actual está atestiguado (DRAE 2014), s.v. hijo, hijo de puta, m. y f. vulg. 'mala persona'. U. c. insulto.

El significado registrado en el corpus es el etimológico, atenuado porque puede entenderse 'mala persona', 'vil' y, desde el punto de vista funcional, tiene un valor referencial si bien se halla aminorado por la emotividad del momento y está impregnado de las funciones expresiva y conativa ${ }^{30}$. En determinados contextos -en literatura se registra a partir del siglo $\mathrm{XV}$ - tiene un uso conativo o apelativo ${ }^{31}$ puesto que se profiere como insulto directo contra el interlocutor en una situación de ira o enojo, caso registrado en la pieza hagiográfica estudiada. Los fueros (Madero 1992: 63-68) recogen puta entre los denuestos vedados. Desde la perspectiva de la moral sexual, esta palabra se afirma como injuria (hasta hoy). Es voz cargada de la representación de la lujuria encarnada sobre todo en lo femenino o en lo bestial. En la Edad Media el cuerpo de las mujeres era una "totalidad culpable" y la belleza un peligro fatal que amenazaba el orden social ${ }^{32}$.

Los primeros valores de este término son, por tanto, el referencial y el conativo ${ }^{33}$. Tras estos usos la forma se empleará con valor conativo-expresivo (Castillo Lluch 2006: 2706) ${ }^{34}$. A lo largo de su empleo en la historia va perdiendo el contenido semántico etimológico y

\footnotetext{
${ }^{30}$ Se recoge en la Comedia de Bras Gil y Beringuella de Lucas Fernández la ofensa hydeputa, que afecta al honor moral y también ofrece visos cómicos (Maurizi 1993: 103).

${ }^{31}$ Hay casos en los que se utiliza con valor conativo-expresivo (si el denuesto por antífrasis Vollega a ser apóstrofe cariñoso: "iQue hijo de puta, qué bien lo has hecho") y también expresivo (en ocasiones en las que se utiliza el insulto con valor puramente interjectivo -como ocurre con la expresión clásica: “ $¡ O h$, hideputa!” (Castillo Lluch 2006: 2697-2708).

${ }^{32}$ La lógica de la feminidad en la escritura de los hombres era puramente corporal, mientras que en la literatura didáctica estaba vinculada a las endebleces o imperfecciones que hacía que, por ejemplo, fueran consideradas ineptas o cobardes. Por otro lado, en el derecho medieval, la referencia al padre sobre la que se articula la injuria tiene dos contenidos: uno concierne a la legitimidad (fijo de nade, fornezino) y el otro a la identidad del padre (fjo de fodido). En cuanto al primero, una madre siempre sabe que un hijo es suyo, es un "lugar inevitable" y, según los fueros y las Partidas, está obligada a hacerse cargo de él. No así el padre que no tiene obligación hacia los hijos nacidos del adulterio, el incesto o la fornicación, ya que este hombre nunca estará seguro de ser el genitor. La legitimidad del nacimiento se encuentra, por ejemplo, en El Conde Lucanor, de don Juan Manuel ("De lo que contesció a un rey con los burladores que fizieron el pańo"). Recordemos que en literatura hay bastardos heroicos, como Mudarra o Ramiro (Madero 1992: 109).

${ }_{33}$ Tenemos ejemplos de valor conativo en La Celestina y responden a tres casos de fideputa, registrados como apartes: dos los profiere Sempronio, y el otro, Elicia.

${ }^{34}$ Se atestigua este empleo en el Quijote, si bien se añade un uso metalingüístico (Castillo Lluch 2006: 26992700). Por otro lado, la misma autora indica que el paso del sintagma nominal fijo de puta a la interjección impropia ¡hideputa! en español clásico responde a un proceso de lexicalización, propiciado por una morfología favorable unido a la fuerte expresividad del insulto, aunque su intensidad semántica y la desaparición de la forma apocopada hi incidieron en la pérdida de la interjección (Castillo Lluch 2006: 2706-2707).
} 
se convierte en interjección impropia, si bien nunca desaparece completamente su sentido primigenio, aunque se atenúe (según apreciamos en nuestro caso).

\section{Conclusiones}

Las ofensas verbales recogidas en los autos hagiográficos del Códice de Autos Viejos conforman un corpus cuyo análisis ofrece útiles datos para la historia de la lengua. La necesaria relación de interdependencia establecida entre las formas lingüísticas y el contexto comunicativo en el que se emplean ha motivado que se aborden las imprecaciones desde una perspectiva complementaria pragmático-semántica en la que se analizan las voces como elementos lingüísticos interrelacionados con su contexto comunicativo. Este enfoque ha permitido valorar no solo las consideraciones sociales que ofrecen los improperios en sus diversos contextos, sino también sus funciones comunicativas como actos de habla junto con sus valores semánticos.

Dentro de la moral cristiana, los insultos son considerados pecados de la lengua promovidos por la ira (pecado capital). Los recogidos en el trabajo corresponden a la contumelia, la injuria de palabra -considerada grave-, que se realiza en presencia del injuriado y en la que el denuesto designa algún defecto de culpa.

Las imprecaciones en teatro no abundan en esta centuria por evidentes motivos de decoro; es más, el adoctrinamiento de la moral cristiana es uno de los objetivos fundamentales de estas piezas sacras. No obstante, a la luz de lo estudiado el patetismo que manifiestan algunas injurias refuerza en el espectador inculto atracción hacia la insólita peripecia que se desarrolla ante sus ojos, mantiene su atención y produce el deseado efecto catártico de la escenificación.

Las ofensas son referidas -de forma general- a la calidad moral del individuo, concretamente en situación de ira causada por la injusticia, crueldad o violencia representadas. Se aprecia un insulto directo, no siempre codificado que, desde perspectiva comunicativa, refuerza la acción con un léxico socialmente considerado ofensivo y grosero. En cuanto a las funciones del lenguaje empleadas, las más utilizadas son la conativa o apelativa junto con la expresiva o emotiva: el hablante expresa con el improperio su enojo con una fuerza ilocutiva que refuerza la tensión. En la formación de los denuestos se emplean recursos morfológicos (sufijación: cochinuelo), sintácticos (sintagma que corresponde a una interjección impropia: hi de puta) y semánticos (metáfora: animal). Son particularmente numerosos los equivalentes a 'inmoral', es decir, que reprochan algún aspecto del comportamiento individual condenado por la sociedad (dañado o maldito). En este sentido, el insulto apunta al concepto de lo que ha sido sancionado socialmente (autoridad, religión, honorabilidad...).

El campo conceptual del insulto se ha organizado atendiendo a los semas que comparten las voces y se ha estructurado en esferas conceptuales. Esta taxonomía agrupa los rasgos semánticos coincidentes que responden a irracionalidad (animal, cochinuelo), rudeza o grosería (bruto, grosero, salvaje), maldad (malvado, mezquino, perverso), despropósito 
(desatinado, desdichado), fingimiento o traición (falso, traidor), condena divina (dañado, maldito), abuso de poder (tirano) y alusión familiar ( $h i$ de puta). Predominan en este contexto literario religioso las ofensas que ponen énfasis en el comportamiento irracional del hombre y en su crueldad (animal, salvaje...).

A la luz de estos datos, consideramos que estas "necesarias injurias" ofrecen creaciones léxicas precisas para calificar personajes y situaciones con gran fuerza expresiva y se hallan tamizadas por el decoro teatral de la época y el ejercicio de "transcripción de oralidad". El insulto llena de connotaciones negativas la palabra escenificada, esto es, dramatizada ante un público que debe ser educado en la ortodoxia cristiana; la palabra malsonante la emplean los mártires para defenderse y los verdugos para descalificarse, en un ambiente de comunión eucarística que aproxima la lengua y su uso al pueblo, esto es, al espectador. Asimismo, contribuye el denuesto a engrandecer a los personajes maltratados convirtiéndolos en paradigmas de la religión defendida a ultranza en el contexto de una sociedad cuyas fiestas giran en torno al adoctrinamiento popular.

\section{Obras citadas}

Alonso, Martín. 1986. Diccionario Medieval Español. Desde las Glosas Emilianenses y Silenses (S. $X)$ hasta el siglo XV. Salamanca: Universidad Pontificia de Salamanca. 2 vols.

Anónimo. Traducción de la "Historia de Jerusalem abreviada" de Jacobo de Vitriaco. Herrera, M. Teresa y Sánchez, M. Nieves. ed. 2000. Salamanca: Universidad de Salamanca.

Ariza, Manuel. 1998. "Lengua y sociedad en el Siglo de Oro (un apunte)", en Hernández, César y Alarcos, Emilio (coords.), Homenaje al profesor Emilio Alarcos García en el centenario de su nacimiento: 1895-1995. Valladolid: Junta de Castilla y León, Consejería de Educación y Cultura-Universidad de Valladolid, Servicio de Publicaciones e Intercambio Científico. 217-225.

. 2009. "Insulte usted sabiendo lo que dice", en Luque, Luis (coord.), Léxico español actual II. Università Ca’Foscari di Venezia. 31-48.

. 2008. Insulte usted sabiendo lo que dice y otros estudios sobre el léxico. Madrid: Arco/ Libros.

. 1983. "La lengua en los debates medievales (Género y lengua literarios)", en Serta Philologica F. Lázaro Carreter. Estudios de lingüistica y lengua literaria. Vol. I. Madrid: Cátedra. 9-65.

Bajtin, Mijail. ed. 1995. La cultura popular en la Edad Media y en el Renacimiento. El contexto de François Rabelais. Madrid: Alianza Editorial.

Baldinger, Kurt. 1977. Teoría semántica. Hacia una semántica moderna. Madrid: Alcalá.

Briz, Antonio. 1996. El español coloquial: Situación y uso. Madrid: Arco/Libros.

Bustos Tovar, José Jesús de. 1995. "De la oralidad a la escritura”, en Cortés, Luis (ed.), El español coloquial. Actas del I Simposio sobre análisis del discurso oral. 11-28.

Casagrande, Carla y Vecchio, Silvana. 1991. Les péchés de la langue. Discipline et éthique de 
la parole dans la culture médiévale. Paris: Le Cerf.

Castilllo Lluch, Mónica. 2006. "Del denuesto a la interjección: la historia de la expresión fijo de puta". Actas del VI Congreso Internacional de Historia de la Lengua Española. Madrid: Arco/Libros, vol. III. 2697-2708.

. 2004. "De verbo vedado: consideraciones lingüísticas sobre la agresión verbal y su expresión en castellano medieval". Cahiers de linguistique et de civilisation hispaniques médiévales 27: 23-36.

Catecismo de la Iglesia Católica. < htt://www.vatican.va/archive/catechism_sp/index_ sp.html> [Web 28 de febrero de 2017].

Cazal, Françoise. 2004. "El santo como elemento moderador de los pecados de la lengua en el Pastor de Diego Sánchez de Badajoz”. Criticón 92: 85-97.

Chauchadis, Claude. 2004. "Virtudes y pecados de la lengua: Sebastián de Covarrubias y Martín de Azpilicueta". Criticón 92: 39-45.

Códice de Autos Viejos. 1988. Selección, edición, introducción y notas de Miguel Ángel Pérez Priego. Madrid: Castalia.

Corominas, Joan y Pascual, José Antonio. 1993. Diccionario Crítico Etimológico Castellano e Hispánico (DCECH). Madrid: Gredos. 6 vols.

Covarrubias, Sebastián de. ed. 2006. Tesoro de la Lengua Castellana o Española. Ed. integral e ilustrada de I. Arellano y R. Zafra. Madrid: Universidad de Navarra-Editorial Iberoamericana.

Domínguez Matito, Francisco y Martínez Berbel, Juan Antonio (eds.). 2012. La Biblia en el teatro español. Vigo: Fundación San Millán de La Cogolla-Editorial Academia del Hispanismo.

Fernández Rodríguez, Natalia. 2013. "Comicidad y devoción: la risa festiva en la comedia hagiográfica de Lope de Vega”. Hipogrifo 1: 185-199.

González Ollé, Fernando. 1962. Los sufijos diminutivos en castellano medieval. RFE-Anejo LXXV. Madrid: CSIC.

Jakobson, Roman. 1975. Ensayos de lingüistica general. Barcelona: Seix-Barral.

Madero, Marta. 1992. Manos violentas, palabras vedadas: la injuria en Castilla y León (siglos XIII-XV). Madrid: Taurus Ediciones.

Maurizi, Françoise. 1993. "Langue et discours: La pulla dans le théâtre de la fin du XVèmeDebut du XVIème siècle”. Voces 4: 97-105.

Montero, Emilio. 2008. "Transgresiones sexuales, tradiciones discursivas y oralidad en el castellano medieval". Cuadernos del CEMyR 16: 145-165.

. 2007. "Palabras malas y villanas (Alfonso X: Partidas). La oralidad en las tradiciones discursivas jurídicas", en Cortés, L. María (coord.), Discurso y oralidad: homenaje al profesor José Jesús de Bustos Tovar. Vol. I. Madrid: Arco / Libros. 391-400. . 2000. "El tabú, el eufemismo y las hablas jergales", en Alvar, Manuel (dir.), Introducción a la lingüistica española. Barcelona: Ariel. 547-563.

Nebrija, Elio A. de. ed. 1989. Vocabulario español-latino. Facsímil de la primera edición. Madrid: Real Academia Española. 
Nieto Jiménez, Lidio y Alvar Ezquerra, Manuel. 2007. Nuevo Tesoro Lexicográfico del Espanol (S. XIV-1726). Madrid: Real Academia-Arco/libros. 11 vols.

Pérez-Salazar, Carmela, Tabernero, Cristina y Usunáriz, Jesús María (eds.). 2013. Los poderes de la palabra. El improperio en la cultura hispánica del Siglo de Oro. New York, Bern, Berlin, Bruxelles, Frankfurt am Main, Oxford, Wien: Peter Lang.

Pons Rodríguez, Lola. 2007. "Cesarán las palabras: la lengua de los diálogos en un texto cuatrocentistas”. Cahiers d'Études Hispaniques Médiévales 30: 289-320.

Real Academia Española. 2014. Diccionario de la Lengua Española (DRAE). Barcelona: Espasa Libros. 23. ${ }^{\mathrm{a}}$ ed.

Real Academia Española. Banco de datos (CORDE) [en línea]. Corpus diacrónico del español. http://www.rae.es. Web 26 de febrero de 2017.

Real Academia Española. Nuevo Tesoro Lexicográfico de la Lengua Española. < http://buscon. rae.es>. Web 28 de febrero de 2017.

Real Academia Española. ed. 1969. Diccionario de Autoridades (edición facsímil de la de 1726-1739). Madrid: Gredos. 3 vols.

Reyes Peña, Mercedes de los. 2003. "El Códice de autos viejos y el teatro religioso en la segunda mitad del siglo XVI”, 389-430. En J. Huerta Calvo (dir.), Historia del teatro español, vol. I. De la Edad Media a los Siglos de Oro. Madrid: Gredos. . 2001. "La primera réplica en las obras hagiográficas del Códice de Autos Viejos". Criticón 83: 47-59.

. 1988. El "Códice de Autos Viejos". Un estudio de historia literaria. Sevilla: Alfar. 3 vols.

Rodríguez, Teresa. 2011. "Usos y funciones de las paremias en un discurso teatral: el Códice de Autos Viejos (segunda mitad del XVI)". Paremia 20: 127-138.

Rouanet, Léo, ed. 1979. Colección de autos, farsas y coloquios del siglo XVI. Hildesheim-New York: Georg Olms (1. a impr., Barcelona-Madrid, 1901). 4 vols.

Tabernero, Cristina. 2013. "Consideración lingüística y social de la injuria en el Tesoro de Covarrubias”. Estudios Filológicos 52: 143-161.

. 2011. "Injurias, maldiciones y juramentos en la lengua española del siglo XVI". Revista de Lexicografía XVI: 101-122.

Tomás de Aquino, Santo, ed. 1964. Suma Teológica. Madrid: BAE. 1. ${ }^{\mathrm{a}}$ ed.

Ugarte Ballester, Xus. 2011. "Ensayo de descalificaciones y maldiciones personales en Celestina y en la traducción catalana de Antoni Balbuena”. Celestinesca 35: 137-158.

Usunáriz, Jesús María. 2013. "Limpios de mala raza”, en Pérez-Salazar, C., Tabernero, C. y Usunáriz, J. M. (eds.), Los poderes de la palabra. El improperio en la cultura hispánica del Siglo de Oro. New York, Bern, Berlin, Bruxelles, Frankfurt am Main, Oxford, Wien: Peter Lang. 277-297. 
